\title{
Emotion processing and regulation in major depressive disorder: A 7T resting-state fMRI study
}

\author{
Amir Ebneabbasi $^{1,2}$ - $\mid$ Mostafa Mahdipour ${ }^{1}$ | Vahid Nejati ${ }^{2}$ | Meng Li $\mathrm{Li}^{3,4}$ | \\ Thomas Liebe $^{3}$ | Lejla Colic ${ }^{3}$ | Anna Linda Leutritz ${ }^{3,5}$ ( ) Matthias Vogel ${ }^{3,7}$ | \\ Mojtaba Zarei ${ }^{1}$ () | Martin Walter ${ }^{3,4,6}$ @ | Masoud Tahmasian ${ }^{1} \odot$
}

${ }^{1}$ Institute of Medical Science and Technology, Shahid Beheshti University, Tehran, Iran

${ }^{2}$ Department of Psychology, Faculty of Psychology and Educational Sciences, Shahid Beheshti University, Tehran, Iran

${ }^{3}$ Clinical Affective Neuroimaging Laboratory, Otto von Guericke University, Magdeburg, Germany

${ }^{4}$ Department of Psychiatry and

Psychotherapy, Jena University Hospital, Jena, Germany

${ }^{5}$ Department of Psychiatry, Psychosomatic Medicine and Psychotherapy, University Hospital, University of Würzburg, Würzburg, Germany

${ }^{6}$ Leibniz Institute for Neurobiology,

Magdeburg, Germany

${ }^{7}$ University Clinic for Psychosomatic Medicine and Psychotherapy, Magdeburg, Germany

\section{Correspondence}

Masoud Tahmasian, Institute of Medical Science and Technology, Shahid Beheshti University, Daneshjou Boulevard, Velenjak, P.O. Box 1983969411, Tehran, Iran.

Email: m_tahmasian@sbu.ac.ir

\begin{abstract}
Dysfunctions in bottom-up emotion processing (EP), as well as top-down emotion regulation (ER) are prominent features in pathophysiology of major depressive disorder (MDD). Nonetheless, it is not clear whether EP- and ER-related areas are regionally and/or connectively disturbed in MDD. In addition, it is yet to be known how EP- and ER-related areas are interactively linked to regulatory behavior, and whether this interaction is disrupted in MDD. In our study, regional amplitude of low frequency fluctuations (ALFF) and whole-brain functional connectivity (FC) of meta-analytic-driven EP- and ER-related areas were compared between 32 healthy controls $(\mathrm{HC})$ and 20 MDD patients. Then, we aimed to investigate whether the EP-related areas can predict the ER-related areas and regulatory behavior in both groups. Finally, the brain-behavior correlations between the EP- and ER-related areas and depression severity were assessed. We found that: (a) affective areas are regionally and/or connectively disturbed in MDD; (b) EP-ER interaction seems to be disrupted in MDD; overburden of emotional reactivity in amygdala may inversely affect cognitive control processes in prefrontal cortices, which leads to diminished regulatory actions. (c) Depression severity is correlated with FC of affective areas. Our findings shed new lights on the neural underpinning of affective dysfunctions in depression.
\end{abstract}

\section{KEYWORDS}

amplitude of low frequency fluctuations, emotion processing, emotion regulation, functional connectivity, major depressive disorder

\section{1 | INTRODUCTION}

Major depressive disorder (MDD), as the most common psychiatric disorder, is the leading cause of disability worldwide (Friedrich, 2017). Emotional dysfunctions in MDD patients are associated with biased processing and impaired regulation of affective stimuli (Joormann \& Stanton, 2016; LeMoult \& Gotlib, 2018). Emotion processing (EP) impairments are mainly manifested by excessive attention towards negative events and nonadaptive interpretation of ambiguous situations (Beck \& Bredemeier, 2016; Bermpohl et al., 2009). In

This is an open access article under the terms of the Creative Commons Attribution-NonCommercial-NoDerivs License, which permits use and distribution in any medium, provided the original work is properly cited, the use is non-commercial and no modifications or adaptations are made.

(c) 2020 The Authors. Human Brain Mapping published by Wiley Periodicals LLC. 
addition, emotion regulation (ER) impairments are widely related to insufficient suppression of negative affect and inadequate savoring of positive ones (Joormann \& Gotlib, 2010; Liu \& Thompson, 2017).

In healthy individuals, the neural underpinnings of EP and ER have been extensively interrogated across heterogeneous task-based fMRI experiments, and quantitatively consolidated for spatial convergence using meta-analytic approaches (Buhle et al., 2014; Stevens \& Hamann, 2012). Two robust meta-analyses not only revealed the regional basis of EP (Riedel et al., 2018) and ER (Kohn et al., 2014), but also proposed step-wise heuristic models. The former leveraged a datadriven method in order to classify a wide range of EP experiments according to similar brain activation patterns. Thereby, five large-scale brain networks were delineated and functionally decoded as follows: (a) an internal or external stimulus is perceived in the visual and (b) auditory cortices; (c) the salient information of stimulus is processed in the insula, anterior cingulate cortex (ACC), and subcortical regions; (d) the self-referential importance of the stimulus is appraised in the medial prefrontal and posterior cingulate cortex (PCC); (e) the emotional reaction is generated in the amygdala and fusiform gyri (Riedel et al., 2018). In addition, the latter integrated the existing ER experiments into three distinct neural subtracts, behaviorally inferenced as follows: (a) evaluation of regulation in the ventrolateral prefrontal cortex (VLPFC); (b) initiation of regulation in the dorsolateral prefrontal cortex (DLPFC); and (c) execution of regulation in the angular gyrus, pre-supplementary motor area (pre-SMA) and SMA (Kohn et al., 2014). Interestingly, a growing body of literature highlighted the importance of interacting brain systems implicated in bottom-up EP and top-down ER (Kelley, Wagner, \& Heatherton, 2015; Ochsner, Silvers, \& Buhle, 2012). Indeed, it seems that EP and ER are not distinct but rather interrelated processes (Morawetz, Alexandrowicz, \& Heekeren, 2017; Morawetz, Bode, Baudewig, \& Heekeren, 2017). A recent mediation model suggested that higher amygdala reactivity prompts greater prefrontal activity, which in turn generates and/or reflects greater regulatory behavior (Doré, Weber, \& Ochsner, 2017).

In MDD, the abnormal activation of EP- and ER-related areas have been extensively reported (Heller et al., 2013; Kanske, Heissler, Schönfelder, \& Wessa, 2012; LeWinn et al., 2018; Tahmasian et al., 2013; Walter, 2017). Previous reviews (Jaworska, Yang, Knott, \& MacQueen, 2015; Joormann \& Stanton, 2016; Park et al., 2019; Rive et al., 2013) and meta-analyses (Hamilton et al., 2012; Palmer, Crewther, \& Carey, 2015; Picó-Pérez, Radua, Steward, Menchón, \& Soriano-Mas, 2017; Schulze, Schulze, Renneberg, Schmahl, \& Niedtfeld, 2019) demonstrated hyperactivity of the amygdala and hypoactivity of the lateral prefrontal cortex during exposure to negative stimuli, which implies the augmented emotional reactivity and diminished ability to downregulation, respectively (Also see Ferri et al., 2017; Wolfensberger, Veltman, Hoogendijk, Boomsma, \& de Geus, 2008; Young et al., 2017) for blunted amygdala reactivity, (Rive et al., 2013) for compensatory prefrontal recruitment and (Müller et al., 2017; Saberi, Mohammadi, Zarei, Eickhoff, \& Tahmasian, 2020) for meta-analytic divergence in MDD). Affective dysfunctions in MDD can be also observed in localizable and whole-brain resting- state fMRI metrics e.g., amplitude of low frequency fluctuations (ALFF) (Cheng et al., 2019; Song, Shen, Mu, Mao, \& Wang, 2020) and functional connectivity (FC) (He et al., 2019; Song, Zhang, \& Huang, 2016). Neuroimaging meta-analyses on ALFF studies pointed to accentuated processing of salient information in the insula/ACC (Li et al., 2017; Wang et al., 2017; Zhou et al., 2017), augmented emotional reactivity in the amygdala (Ma et al., 2019) and diminished cognitive control in the prefrontal cortex (Wang et al., 2017; Zhong, $\mathrm{Pu}, \&$ Yao, 2016) (Also see (Gray, Müller, Eickhoff, \& Fox, 2020) which did not replicate previous ALFF findings in MDD). In addition, a previous review (Mulders, van Eijndhoven, Schene, Beckmann, \& Tendolkar, 2015) and a meta-analysis (Kaiser, Andrews-Hanna, Wager, \& Pizzagalli, 2015) showed altered FC in the neural networks underlying the processing and cognitive control of emotions. Importantly, reduced coupling of amygdala-prefrontal activation in MDD, in contrast to healthy individuals, may suggest a deficient EP-ER interaction (Erk et al., 2010).

Nonetheless, it is not clear which hypothesis-driven EP(i.e., visual, auditory, attention, appraisal and response) (Riedel et al., 2018) and ER-related areas (i.e., evaluation, initiation, and execution) (Kohn et al., 2014) are regionally/connectively disturbed in MDD. Such a model-based approach has the major advantage of targeting the consistent brain areas which are obtained from statistical convergence across previous neuroimaging findings (Schilbach et al., 2014). In addition, it is yet to be known how EP- and ERrelated areas are interactively linked to regulatory behavior (Doré et al., 2017), and whether this interaction is disrupted in MDD. Furthermore, the association of depression severity with affective circuitries have been previously highlighted (He et al., 2019), but needs to be further addressed with model-based EP- and ER-related areas. Importantly, our knowledge of depression neuropathology has been widely constructed using 3Tesla (3T) imaging setups, however, the clinical utility of ultra-high field $7 \mathrm{~T}$ scanner is predominantly recommended considering enhanced signal-to-noise ratio (SNR) (Beisteiner et al., 2011) and amplitude of signal change (van der Zwaag et al., 2009). Specifically, the recent evidences of 7T imaging revealed dysfunctional affective circuitries, which were not detectable with lower field strengths (Morris et al., 2019; Sladky et al., 2013).

Therefore, using a 7T functional imaging device, our study was designed (a) to compare regional ALFF and whole-brain FC of EP(Riedel et al., 2018) and ER-related areas (Kohn et al., 2014) between healthy controls $(\mathrm{HC})$ and MDD patients (b) to interrogate the interactions of EP- and ER-related areas in HC and MDD; (c) to investigate the brain-behavior correlation between the EP- and ER-related areas and MDD severity. Firstly, we hypothesized that EP- and ER-related areas are regionally and/or connectively disturbed in MDD. In particular, we expected sensory/attention biases, appraisal/response exaggerations and insufficient evaluation/initiation of regulation. Secondly, we hypothesized a disrupted pattern of EP-ER interaction in MDD. Thirdly, we expected that EP- and ER-related alterations are linked with severity of MDD. 


\section{2 | METHODS}

\section{1 | Subjects}

Twenty-five MDD patients and $37 \mathrm{HC}$ were recruited through local advertisements in Otto-von-Guericke University Magdeburg. All the participants were right-handed native German speakers (Table 1). The diagnosis of unipolar major depression was made by a clinical psychiatrist (M. W.) according to ICD-10. Exclusion criteria for all subjects were acute physical illness, substance abuse or dependence, history of traumatic head injury, any other psychiatric or neurological disorders and scanning issues such as claustrophobia or having metal object in the body. Some subjects were excluded due to excessive head motions during scanning. Finally, data of 20 MDD patients and $32 \mathrm{HC}$ were analyzed. This study was approved by the local Ethics Committee of Otto-von-Guericke University Magdeburg and all participants signed an informed consent.

\section{2 | Psychometric scales}

Depression severity was assessed with the 17-items Hamilton Depression Rating Scale (HDRS-17). Regulatory behavior was examined by the German questionnaire "Skalen zum Erleben von Emotionen (SEE)" (Behr and Becker, 2004). SEE measures emotion experience in seven subscales: (a) emotion acceptance, (b) emotion overload experience, (c) emotion deficiency experience, (d) somatic symbolization of emotions, (e) imaginative symbolization of emotions, (f) emotion regulation experience, (g) self-control experience. We used the "emotion regulation experience" subscale of SEE. Better ability to regulate positive and/or negative affect is reflected in the greater scores. Of note, SEE is a well-established scale with a sufficient internal consistency (Cronbach alpha $=.70$ ), robust testretest stability (correlation coefficient $=.81$, after 10 weeks), and satisfactory convergent/discriminant validity (Behr and Becker, 2012).

\section{3 | Resting-state image acquisition}

Magnetic resonance images were acquired through a high resolution 7T scanner (Siemens, Erlangen, Germany) with a 32-channel head array coil. Participants were instructed to stay relaxed and awake, while having their eyes closed during the scanning session. In order to reduce head movements, the heads of subjects were fixed using foam pads. Anatomical images were collected with an MPRAGE sequence $\left(\mathrm{TE}=2.73 \mathrm{~ms}, \mathrm{TR}=2,300 \mathrm{~ms}, \mathrm{TI}=1,050 \mathrm{~ms}\right.$, flip angle $=5^{\circ}$, band width $=150 \mathrm{~Hz} /$ pixel, isotropic voxel size $=0.8 \mathrm{~mm}$ ). Functional images were acquired with an EPI sequence $(T E=22 \mathrm{~ms}$, $\mathrm{TR}=2,800 \mathrm{~ms}$, flip angle $=80^{\circ}$, bandwidth $=2,246 \mathrm{~Hz} /$ pixel, isotropic voxel size $=2 \mathrm{~mm}, 280$ timepoints, 62 interleaved ascending axial slices, acquisition time $=13 \mathrm{~min}$ ).

\section{4 | Preprocessing}

First, MRI images were visually checked for distortion artifacts. Preprocessing steps were performed using DPARSF 4.4 (Yan, 2010) running on MATLAB 2018 . The first five volumes were discarded because of magnetization destabilization. Functional images were temporary corrected, spatially realigned, and co-registered to the structural images. The functional images were then normalized to the Montreal Neurological Institute (MNI) template $(2 * 2 * 2)$ and smoothed with a $6 \mathrm{~mm}$ full-width-half-maximum (FWHM) Gaussian kernel. The structural images were segmented to gray matter (GM), white matter
TABLE 1 Demographic and clinical variables in MDD and $\mathrm{HC}$ groups

\begin{tabular}{|lllll|}
\hline & MDD & HC & T/X $\mathbf{X}^{2}$ value & $p$-value \\
\hline Sample size & 20 & 32 & - & - \\
\hline Age (years) & $40.05 \pm 13.828$ & $29.03 \pm 6.832$ & $\mathrm{t}=-3.319$ & .003 \\
\hline Gender (M: F) & $8: 12$ & $19: 13$ & $\mathrm{X}^{2}=1.851$ & .174 \\
\hline Medication (n) & & & & \\
\hline NaSSA & 1 & - & - & - \\
\hline SSRI & 2 & - & - & - \\
\hline SSNRI & 3 & - & - & - \\
\hline Tricyclic & 2 & - & - & - \\
\hline Non-declared & 6 & - & - & - \\
\hline Naive & 6 & - & - & - \\
\hline Psychometrics (mean \pm SD) & & & & \\
\hline HDRS-17 & $21.35 \pm 4.31$ & $1.31 \pm 2.03$ & $\mathrm{t}=-19.471$ & .0001 \\
\hline SEE & $8.40 \pm 3.658$ & $13.13 \pm 2.862$ & $\mathrm{t}=4.224$ & .0001 \\
\hline
\end{tabular}

Abbreviations: HC, healthy control; HDRS, hamilton depression rating scale; MDD, major depressive disorder; NaSSA, noradrenergic and selective serotonergic antidepressant; SEE, skalen zum erleben von emotionen; SSNRI, selective serotonin and norepinephrine reuptake inhibitor; SSRI, selective serotonin reuptake inhibitor. 
(WM) and cerebrospinal fluid (CSF) and normalized to MNI space $\left(2^{*} 2^{*} 2\right)$. In addition, nuisance covariates (i.e., Friston-24 motion parameters, WM and CSF signal) were regressed out. Finally, the linear trend of the time-series was removed and a band-pass filter (.01-.10 Hz) was applied. Five MDD patients and five $\mathrm{HC}$ with excessive head motion during scanning were excluded (translation $>1.5 \mathrm{~mm}$ and rotation $>1.5$ angle in any direction). Of note, average root mean squared (RMS) ( $\mathrm{HC}=.0715, \mathrm{MDD}=.0860, \mathrm{t}=-1.466, p=.149)$ and mean frame-wise displacement (FD) (Jenkinson, Bannister, Brady, \& Smith, 2002) $(\mathrm{HC}=.0405, \mathrm{MDD}=.0490, \mathrm{t}=-1.549, p=.134)$ were not statistically differed between MDD and HC groups.

\section{5 | Regional ALFF and whole-brain FC measurements}

Five EP- and three ER-related seeds (Table S1 and Figure S1) were respectively selected from the meta-analytic-driven maps of Riedel et al., (2018) (https://anima.inm7.de/studies/Riedel_Emotion_ MetaAnalysis_2018) and Kohn et al., (2014) (https://anima.inm7.de/ studies/Kohn_EmotionRegulation_2014). Each EP-related seed consisted of several concatenated regions: (a) visual (middle frontal gyrus [MFG], lingual gyrus and left cuneus), (b) auditory (left insula, superior temporal gyrus [STG] and right cingulate gyrus), (3) attention (frontal gyrus, insula, cingulate gyrus and thalamus), (d) appraisal (MFG and left posterior cingulate cortex [PCC]) and (e) response (right middle temporal gyrus [MTG], amygdala and left fusiform gyrus). In addition, each ER-related seed consisted of several concatenated regions: (a) evaluation (VLPFC as the functional surrogate of left and right inferior frontal gyrus [IFG]), (b) initiation (DLPFC as the functional surrogate of pre-central gyrus and right MFG) and (c) execution (angular gyrus, pre-supplementary motor area [pre-SMA] and SMA). Our largescale seeds were not compartmentalized to provide a more complete and coherent appreciation of the affective substrates (see [Lindquist, Wager, Kober, Bliss-Moreau, \& Barrett, 2012; Morawetz et al., 2020] for existing debate regarding the locationist vs. constructionist perspectives, where the former assumes affective processes as independent neurobiological foundations, and the latter assumes affective processes as consequences of network interactions). Therefore, the ALFF and FC values were averaged across the regions associated with each large-scale seed.

Individual ALFF and FC calculation was performed using DPARSF $_{4.4}$ (Yan, 2010). First, the time-series of whole-brain voxels were extracted for each subject. Voxel-wise ALFF represented the average square root of power spectrum within $0.01-0.10 \mathrm{~Hz}$ range (Zou et al., 2008). Regional ALFF was calculated using the "explicit masks" of EP- and ER-related areas, which exclude the ALFF analysis to our selected seeds. Besides, whole-brain FC represented the correlation coefficient between the mean time-series of each seed and the time-series of whole-brain voxels. ALFF and FC measures were transformed by Fisher r-to-z transformation for normalization of data distribution. Individual ALFF and FC z-maps were subsequently used for second-level analysis.

\section{6 | Between-group comparison analysis}

Second-level analysis was performed using SPM $_{12}$ (http://www.fil.ion. ecl.ac.uk/spm). Independent two-sample t-tests were used to compare the regional ALFF and whole-brain FC z-maps of EP- and ER-related seeds between MDD and HC groups. Age, gender and mean FD were treated as covariates in our group comparisons. Voxel-forming threshold $(p<.001)$ and cluster extend threshold ( $\mathrm{K}>20$ voxels) were applied. Correction for multiple comparison was performed by family-wise error (FWE) $(p<.05)$. Results that survived Bonferroni correction were considered significant ( $p_{\text {FWE }}<.003$ ) [i.e., $p_{\text {FWE }} / 2$ (ALFF and FC) * 8 (number of seeds)]. SPM anatomy toolbox ${ }_{3}$ (Eickhoff et al., 2005) was used for anatomical identification of the results. Brain figures were plotted using BrainNet Viewer (Xia, Wang, \& He, 2013).

\subsection{Mediation analysis}

A mediation analysis was conducted with structural equation modeling (SEM) in both groups. SEM is consisted of measurement (outer) versus structural (inner) models (Martynova, West, \& Liu, 2018). The measurement model is conceptually similar to factor analysis, consisting of the paths (loadings/weights) as the contribution of observable variables (indicators) to latent constructs (factors). Additionally, the structural model shows the interconnection of latent exogenous (independent), endogenous (dependent) and mediator variables through regression coefficients (Tarka, 2018).

Our mediation analysis was implemented using SmartPLS $_{3}$ (http:// www.smartpls.com). Partial least square (PLS-SEM) is predominantly recommended for predictive/exploratory modeling (Hair, Risher, Sarstedt, \& Ringle, 2019), and importantly, does not necessitate stringent and impractical distributional assumptions (Hair, Ringle, \& Sarstedt, 2013). Since FC results involve a seed and a target region, it could provide some complexities in our mediation model. Instead, ALFF as a localizable metric was eligible to delineate the "pure" interactions of the model-based EP- and ER-related areas. In our model, ALFF values of group-comparison-derived EP-related seed(s) were entered as the indicator(s) of exogenous variable, SEE was selected as the indicator of endogenous variable, and ALFF values of group-comparisonderived ER-related seed(s) were entered as the indicator(s) of mediator variable. Of note, a supplementary analysis was performed to show that our mediation model is not confounded by the second-level covariates (Table S2). This model reveals regression coefficients including direct effects $\left(\beta_{\mathrm{EP} \rightarrow \mathrm{ER}}, \beta_{\mathrm{ER} \rightarrow \mathrm{SEE}}, \beta_{\mathrm{EP} \rightarrow \mathrm{SEE}}\right.$ ), an indirect mediation effect as the multiplication of direct effects $\left(\beta_{\mathrm{EP} \rightarrow \mathrm{ER}}{ }^{*} \beta_{\mathrm{ER} \rightarrow \mathrm{SEE}}\right)$ and a total effect as the summation of direct and indirect effects $\left(\left[\beta_{\mathrm{EP} \rightarrow \mathrm{SEE}}\right]+\left[\beta_{\mathrm{EP} \rightarrow \mathrm{ER}}{ }^{*} \beta\right.\right.$ $E R \rightarrow S E E])$. Since the distributional properties of estimates are not known in PLS, parametric significance tests cannot be used to test whether outer loadings and path coefficients are significant (Streukens \& LeroiWerelds, 2016). Instead, statistical inference would be possible through nonparametric bootstrapping procedure. We set 10,000 subsamples in our bootstrapping analysis as previously advised (Streukens \& LeroiWerelds, 2016). 


\section{8 | Brain-behavior correlation analysis}

The associations of depression severity (HDRS-17) with regional ALFF and whole-brain FC z-maps of EP- and ER-related seeds were assessed using Pearson correlation. Age, gender, and mean FD were treated as covariates. Voxel-forming threshold $(p<.001)$ and cluster extend threshold ( $K>20$ voxels) were applied. Correction for multiple comparison was performed by family-wise error (FWE) $(p<.05)$. Results that survived Bonferroni correction were considered significant ( $p_{\text {FWE }}<.003$ ) [i.e., $p_{\text {FWE }} / 2$ (ALFF and FC) * 8 (number of seeds)].

\section{3 | RESULTS}

\section{1 | Between-group comparison results}

\subsection{1 | Between-group comparisons of regional ALFF and whole-brain FC in EP-related seeds}

MDD patients had an increased ALFF of the response seed (right amygdala) (Table 2 and Figure 1), enhanced FC between the visual seed and medial prefrontal cortex (MPFC), increased FC between the auditory seed and right DLPFC, and reduced FC between the attention seed and right Inferior parietal lobule (IPL). All results survived FWE and Bonferroni correction. Other group-differences were not significant (Table 3 and Figure 2).

\subsection{2 | Between-group comparisons of regional ALFF and whole-brain FC in ER-related seeds}

MDD patients had a decreased ALFF of the initiation seed (left DLPFC) (Table 2 and Figure 1), reduced FC between the evaluation seed and right intra-parietal sulcus (IPS) and reduced FC between the initiation seed and left VLPFC. All results survived FWE and Bonferroni correction (Except left DLPFC). Other group-differences were not significant (Table 3 and Figure 2).

\section{2 | Mediation analysis results}

According to the between-group comparisons of regional ALFF, EP (exogenous variable) was indicated by the ALFF of response seed (right amygdala). Although the initiation seed (left DLPFC) did not survive Bonferroni correction, ER (mediator variable) was indicated by the ALFF of initiation seed (left DLPFC) for further exploration of EPER model (Doré et al., 2017). Regulatory behavior (endogenous variable) was also indicated by the SEE scores. Since our latent variables were represented with a single indicator, path loadings were fixed at one number. We indicated that the second-level covariates (age, gender, and FD) cannot significantly predict the mediator/endogenous variables in both groups (Table S2). In addition, bootstrapping analysis did not show any significant EP-ER findings in HC group (Table 4 and Figure 3). In MDD group, however, higher ALFF of right amygdala predicted lower ALFF of left DLPFC $(\beta=-.604, p<.001)$ and weaker regulatory behavior in total $(\beta=-.391, p<.002)$. Although left DLPFC was not a "full" mediator (i.e., the indirect effect ( $\beta$ Amygdala $\rightarrow$ DLPFC ${ }^{*} \beta$ DLPFC $\rightarrow$ SEE $)$ was non-significant), still it makes the total effect significant (Table 4 and Figure 3).

\section{3 | Brain-behavior correlation results}

\subsection{1 | Correlation of depression severity with regional ALFF and whole-brain FC of EP-related seeds}

Our findings indicated that HRDS-17 is not significantly correlated with the ALFF of EP-related seeds. However, HRDS-17 was

TABLE 2 Altered regional amplitude of low frequency fluctuations of emotion processing and regulation seeds in MDD compared with HC group $(p<.003$, FWE- and Bonferroni-corrected)

\begin{tabular}{|c|c|c|c|c|c|c|c|}
\hline EP/ER & Step & Seed & $P_{\text {FWE }}$ & Cluster size & Target & Contrast & $\mathrm{MNI}_{(\mathrm{X}, \mathrm{Y}, \mathrm{Z})}$ \\
\hline \multirow[t]{4}{*}{ Emotion processing } & Visual & MFG, LG, CUN & $n / s$ & - & - & - & - \\
\hline & Auditory & IC, STG, CG & $\mathrm{n} / \mathrm{s}$ & - & - & - & - \\
\hline & Appraisal & MFG, PCC & $\mathrm{n} / \mathrm{s}$ & - & - & - & - \\
\hline & Response & MTG, AMY, FuG & .003 & 184 & R AMY & $\mathrm{HC}<\mathrm{MDD}$ & $32,-20,-16$ \\
\hline \multirow{2}{*}{ Emotion regulation } & Initiation & DLPFC & .014 & 76 & L DLPFC & $\mathrm{HC}>\mathrm{MDD}$ & $-38,18,46$ \\
\hline & Execution & AG, (pre) SMA & $\mathrm{n} / \mathrm{s}$ & - & - & - & - \\
\hline
\end{tabular}

Note: DLPFC was FWE-corrected and Bonferroni-uncorrected.

Abbreviations: AG, angular gyrus; AMY, amygdala; CG, cingulate gyrus; CUN, cuneus; DLPFC, dorsolateral prefrontal cortex; FG, frontal gyrus; FuG, fusiform gyrus; HC, healthy control; IC, insular cortex; LG, lingual gyrus; MDD, major depressive disorder; MFG, middle frontal gyrus; MTG, middle temporal gyrus; PCC, posterior cingulate cortex; pre-SMA, pre-supplementary motor area and SMA; STG, superior temporal gyrus; TH, thalamus; VLPFC, ventrolateral prefrontal cortex. 


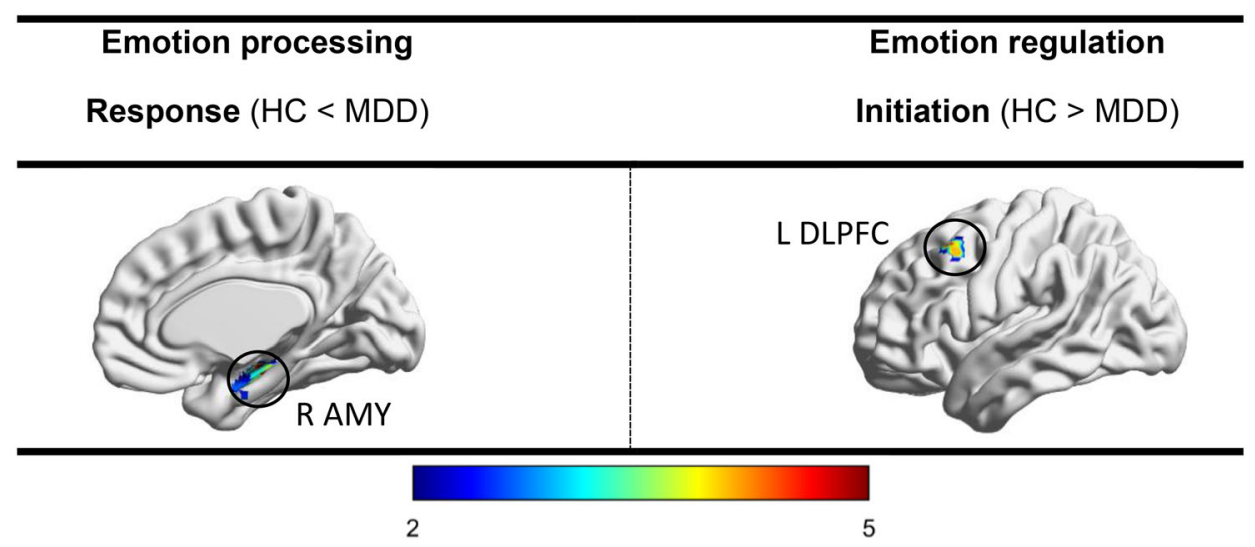

FIGURE 1 Altered regional amplitude of low frequency fluctuations of emotion processing and regulation seeds in MDD compared with HC group $(p<.003$, FWE- and Bonferroni-corrected). Major depressive disorder (MDD), healthy control (HC), amygdala (AMY), dorsolateral prefrontal cortex (DLPFC)

TAB LE 3 Altered whole-brain functional connectivity of emotion processing and regulation seeds in MDD compared with HC group $(p<.003$, FWE- and Bonferroni-corrected)

\begin{tabular}{|c|c|c|c|c|c|c|c|}
\hline EP/ER & Step & Seed & $P_{\text {FWE }}$ & Cluster size & Target & Contrast & $M N I_{(X, Y, Z)}$ \\
\hline \multirow[t]{4}{*}{ Emotion processing } & Visual & MFG, LG, CUN & .001 & 328 & MPFC & $\mathrm{HC}<\mathrm{MDD}$ & $-6,34,58$ \\
\hline & Auditory & IC, STG, CG & .002 & 148 & R DLPFC & $\mathrm{HC}<\mathrm{MDD}$ & $46,40,26$ \\
\hline & Appraisal & MFG, PCC & $\mathrm{n} / \mathrm{s}$ & - & - & - & - \\
\hline & Response & MTG, AMY, FuG & $\mathrm{n} / \mathrm{s}$ & - & - & - & - \\
\hline \multirow{2}{*}{ Emotion regulation } & Initiation & DLPFC & .001 & 293 & L VLPFC & $\mathrm{HC}>\mathrm{MDD}$ & $-42,56,2$ \\
\hline & Execution & AG, (pre) SMA & $\mathrm{n} / \mathrm{s}$ & - & - & - & - \\
\hline
\end{tabular}

Abbreviations: AG, angular gyrus; AMY, amygdala; CG, cingulate gyrus; CUN, cuneus; DLPFC, dorsolateral prefrontal cortex; FG, frontal gyrus; FuG, fusiform gyrus; HC, healthy control; IC, insular cortex; IPL, inferior parietal lobule; IPS, intraparietal sulcus; LG, lingual gyrus; MDD, major depressive disorder; MFG, middle frontal gyrus; MPFC, middle prefrontal cortex; MTG, middle temporal gyrus; PCC, posterior cingulate cortex; pre-SMA, presupplementary motor area and SMA; STG, superior temporal gyrus; TH, thalamus; VLPFC, ventrolateral prefrontal cortex.

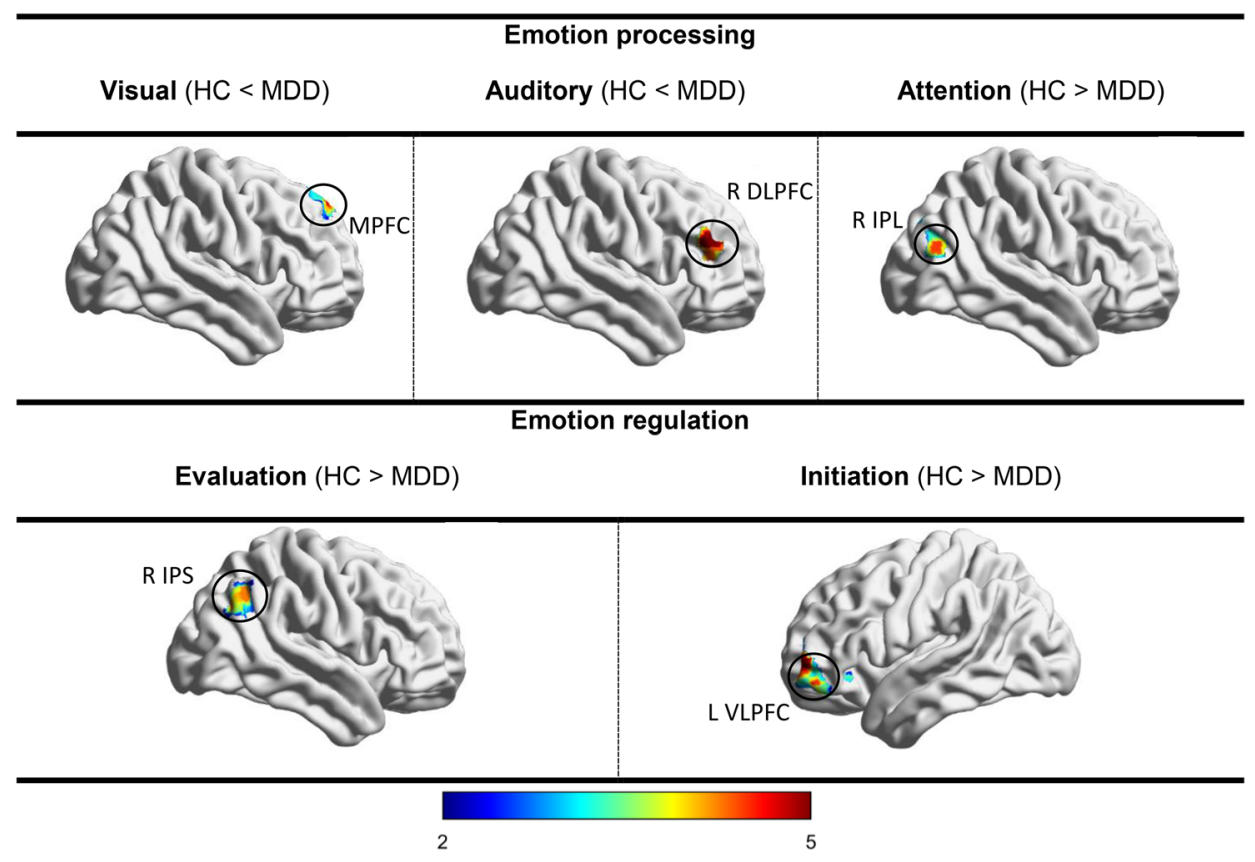

FIGURE 2 Altered whole-brain functional connectivity of emotion processing and regulation seeds in MDD compared with $\mathrm{HC}$ group $(p<.003$, FWE- and Bonferronicorrected). Major depressive disorder (MDD), healthy control (HC), middle prefrontal cortex (MPFC), dorsolateral prefrontal cortex (DLPFC), inferior parietal lobule (IPL), intraparietal sulcus (IPS), ventrolateral prefrontal cortex (VLPFC) 
TABLE 4 Mediation analysis findings in MDD and $\mathrm{HC}$ groups

\begin{tabular}{lll} 
& \multicolumn{1}{l}{ Path coefficient (p-value) } & \\
\cline { 2 - 3 } Effect & MDD & HC \\
\hline iirect & & \\
\hline$E P \rightarrow E R$ & $-.604(.001)$ & $-.165(.308)$ \\
\hline$E R \rightarrow S E E$ & $.305(.318)$ & $-.126(.429)$ \\
\hline$E P \rightarrow S E E$ & $-.198(.504)$ & $-.140(.484)$ \\
\hline Indirect & & $.022(.619)$ \\
$\left(\beta_{E P \rightarrow E R}{ }^{*} \beta_{E R \rightarrow S E E}\right)$ & $-.193(.468)$ & \\
\hline Total & & $-.119(.553)$ \\
\hline$\left.\left(\beta_{E P \rightarrow S E E}\right)+\left(\beta_{E P \rightarrow E R}{ }^{*} \beta_{E R \rightarrow S E E}\right)\right]$ & $-.391(.002)$ & \\
\hline
\end{tabular}

Note: Emotion processing (EP) as exogenous variable is indicated by the amplitude of low frequency fluctuations (ALFF) of response seed (right amygdala), emotion regulation (ER) as mediator variable is indicated by the ALFF of initiation seed (left dorsolateral prefrontal cortex) and regulatory behavior as endogenous variable is indicated by the Skalen zum Erleben von Emotionen (SEE) scores. Direct, indirect, and total effects are shown for major depressive disorder (MDD) and healthy control (HC) groups.

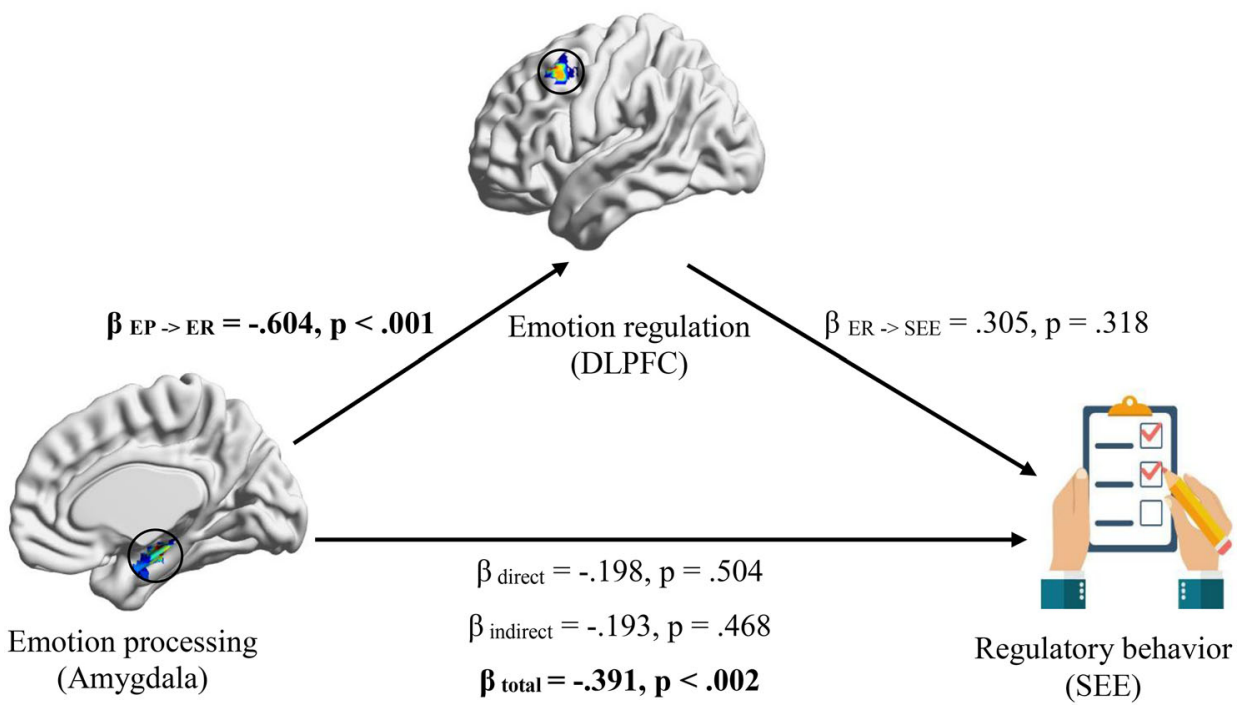

(SEE)
FIGURE 3 Mediation analysis findings in MDD. Emotion processing (exogenous variable) is indicated by the amplitude of low frequency fluctuations (ALFF) of response seed (right amygdala), emotion regulation (mediator variable) is indicated by the ALFF of initiation seed (left dorsolateral prefrontal cortex) and regulatory behavior (endogenous variable) is indicated by the Skalen zum Erleben von Emotionen (SEE) scores. $\beta$ coefficients and $p$-values are presented for MDD group

TAB LE 5 Correlation of depression severity (Hamilton Rating Depression Scale-17) with whole-brain functional connectivity of emotion processing and regulation seeds in MDD group ( $p<.003$, FWE- and Bonferroni-corrected)

\begin{tabular}{|c|c|c|c|c|c|c|c|}
\hline & Step & Seed & $P_{\text {FWE }}$ & Cluster size & Target & Contrast & $\mathrm{MNI}_{(\mathrm{X}, \mathrm{Y}, \mathrm{Z})}$ \\
\hline \multirow[t]{4}{*}{ Emotion processing } & Visual & MFG, LG, CUN & $\mathrm{n} / \mathrm{s}$ & - & - & - & - \\
\hline & Auditory & IC, STG, CG & $\mathrm{n} / \mathrm{s}$ & - & - & - & - \\
\hline & Appraisal & MFG, PCC & $n / s$ & - & - & - & - \\
\hline & Response & MTG, AMY, FuG & $\mathrm{n} / \mathrm{s}$ & - & - & - & - \\
\hline \multirow{2}{*}{ Emotion regulation } & Initiation & DLPFC & .003 & 188 & R VLPFC & Negative correlation & $-46,50,-8$ \\
\hline & Execution & AG, (pre) SMA & $\mathrm{n} / \mathrm{s}$ & - & - & - & - \\
\hline
\end{tabular}

Abbreviations: AG, angular gyrus; AMY, amygdala; CG, cingulate gyrus; CUN, cuneus; DLPFC, dorsolateral prefrontal cortex; FG, frontal gyrus; FuG, fusiform gyrus; HC, healthy control; IC, insular cortex; IPL, inferior parietal lobule; LG, lingual gyrus; MDD, major depressive disorder; MFG, middle frontal gyrus; MPFC, middle prefrontal cortex; MTG, middle temporal gyrus; PCC, posterior cingulate cortex; pre-SMA, pre-supplementary motor area and SMA; STG, superior temporal gyrus; TH, thalamus; VLPFC, ventrolateral prefrontal cortex. 


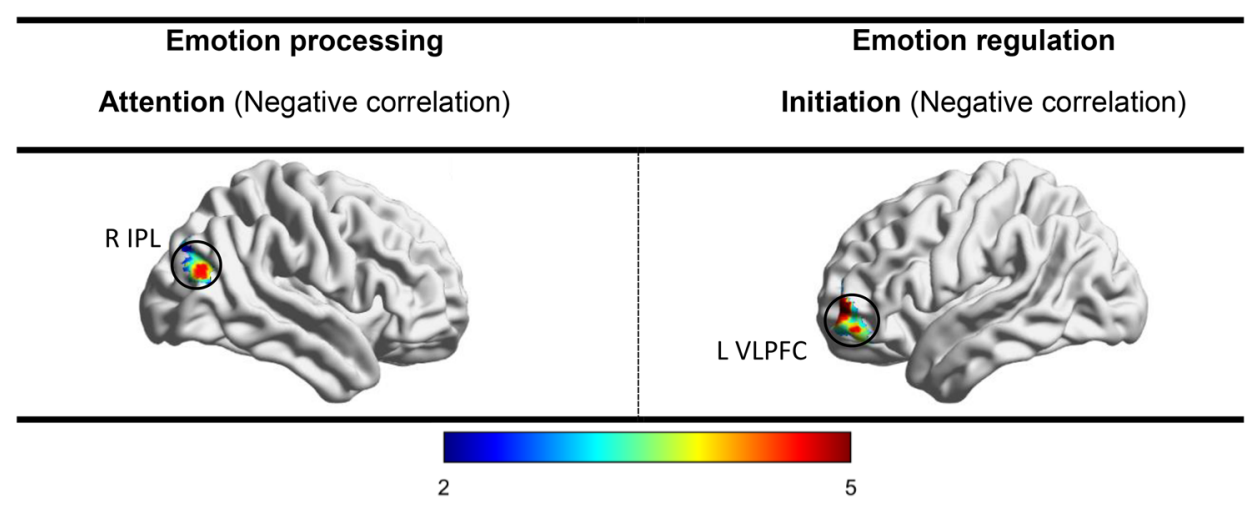

FIGURE 4 Correlation of depression severity (Hamilton Rating Depression Scale-17) with wholebrain functional connectivity of emotion processing and regulation seeds in MDD group $(p<.003$, FWEand Bonferroni-corrected). Major depressive disorder (MDD), inferior parietal lobule (IPL), ventrolateral prefrontal cortex (VLPFC) negatively correlated with FC between the attention seed and right IPL (FWE- and Bonferroni-corrected). Other FC results were not significant (Table 5 and Figure 4).

\subsection{2 | Correlation of depression severity with regional ALFF and whole-brain FC of ER-related seeds}

Our findings indicated that HRDS-17 is not significantly correlated with the ALFF of ER-related seeds. However, HRDS-17 was negatively correlated with FC between the initiation seed and right VLPFC (FWE- and Bonferroni-corrected). Other FC results were not significant (Table 5 and Figure 4).

\section{DISCUSSION}

To our best knowledge, our study provided new evidences for the model-based regional/connectivity alterations of affective areas, the disrupted EP-ER interaction, and the affective neural correlates of depression severity in MDD. Importantly, we aimed to implement a 7T functional imaging setup, well-suited to specify subcortical structures implicated in EP (e.g., amygdala) (Alkemade et al., 2020; Sladky et al., 2013; Walter, Stadler, Tempelmann, Speck, \& Northoff, 2008), which are not efficiently documented using lower fields (Metzger et al., 2010; Morris et al., 2019).

Our regional findings of EP-related seeds revealed an enhanced ALFF of the right amygdala in MDD (Table 2 and Figure 1). The amygdala is generally involved in the encoding of motivationally relevant stimuli (Lindquist et al., 2012), generating the expressive and affective characteristics of the emotional response (Park et al., 2019). Previous MDD meta-analyses pointed to higher activation of amygdala during exposure to negative stimuli (Hamilton et al., 2012; Palmer et al., 2015). The elevated ALFF of amygdala also observed in a resting-state meta-analysis (Ma et al., 2019) which probably provide the susceptibility for prolonged/excessive processing of negative information. Of note, there is evidence that amygdala activity is affected by clinical confounders, that is, symptom severity, state/trait anxiety and medication level (Brakowski et al., 2017; Li et al., 2018) which render inconsistent findings across resting-state studies (Gray et al., 2020; Li et al., 2017; Zhou et al., 2017).

According to our regional findings of ER-related seeds, ALFF of the left DLPFC had a reduction trend in MDD (Table 2 and Figure 1). The DLPFC is routinely associated with the inhibition of subcortical limbic structures (Dixon, Thiruchselvam, Todd, \& Christoff, 2017; Etkin, Büchel, \& Gross, 2015), that is, the contextual modulation of emotional responses (Doré \& Ochsner, 2015; Öner, 2018). Previous MDD reviews highlighted the attenuated activation of prefrontal areas during down-regulation of negative affect (Donofry, Roecklein, Wildes, Miller, \& Erickson, 2016; Zilverstand, Parvaz, \& Goldstein, 2017). The decreased ALFF of prefrontal cortex is also reported in two resting-state meta-analyses (Wang et al., 2017; Zhong et al., 2016) which probably provide the susceptibility for insufficient dampening of the irrelevant emotional responses. It should be noted that prefrontal activity is also affected by clinical confounders (Brakowski et al., 2017; Li et al., 2018). Furthermore, there is some evidence that MDD individuals are likely to involve compensatory prefrontal resources during early/automatic stages of regulation. However, when emotional experience is already passed and voluntary control is necessitated, the additional recruitment of prefrontal structures seems to be impaired (see Rive et al., 2013 for a thorough review).

Searching for the connectivity alterations of EP-related areas, our findings showed an enhanced FC between the visual/auditory seeds and prefrontal areas in MDD (Table 3 and Figure 2). Our model-based visual/auditory seeds are highlighted in the identification and discrimination of internal versus external stimuli (Riedel et al., 2018). Importantly, the causal role of prefrontal areas in top-down modulation of sensory inputs has been demonstrated (Zanto, Rubens, Thangavel, \& Gazzaley, 2011). Previous MDD studies pointed to the amplified modulatory role of prefrontal regions, which is presumably resulted in the sustained anticipation of negative stimuli and/or suppression of positive ones (Park et al., 2019; Rive et al., 2013). We also found a reduced FC between the attention seed and the right Inferior parietal lobule (IPL) in MDD (Table 3 and Figure 2). Our model-driven attention seed (frontal gyrus, insula, cingulate gyrus, and thalamus) is associated with attending to emotionally salient information (Kaiser et al., 2015; Riedel et al., 2018). The parietal lobule is also activated in 
attention switching and gaze shifting (Beevers, Clasen, Stice, \& Schnyer, 2010; Calder et al., 2007). The diminished connectivity of parietal lobule in MDD has been previously reported (Disner, Beevers, Haigh, \& Beck, 2011), which is probably eventuated to dysfunctional negative stimulus disengagement and/or positive stimulus engagement. Unexpectedly, our appraisal seed did not show abnormal FC in MDD (Table 3). This model-driven seed (MFG and PCC, as major hubs of default mode network) is generally implicated in self-relevant interpretation of stimulus meaning (Riedel et al., 2018; Xie et al., 2016). Actually, the ruminative appraisals of MDD patients are generally reflected in the hyperconnectivity of MFG and PCC (Manoliu et al., 2014; Shao et al., 2018). As previously mentioned, we did not compartmentalize the large-scale meta-analytic-driven EP- and ERrelated seeds, and the intra-connectivity of those concatenated areas were not interrogated.

ER-related connectivity findings indicated a reduced FC between the evaluation seed (VLPFC) and intraparietal sulcus (IPS) in MDD (Table 3 and Figure 2). The VLPFC is responsible for evaluating the ongoing emotional response, if necessary, inhibiting an initial appraisal and shifting attention to additional adaptive evidences (Etkin et al., 2015; Kohn et al., 2014). The IPS is also responsible for inhibitory processes (Osada et al., 2019), detecting the priorities of attention focusing (Viviani, 2013). Taken together, it can be inferred that decisions about the regulation necessity, in terms of inhibiting and/or updating the current emotional state, may not be fairly detected in MDD (Joormann \& Stanton, 2016). In addition, our findings indicated a reduced FC between the VLPFC and DLPFC in MDD (Table 3 and Figure 2). The VLPFC is expected to project the regulation urgency to DLPFC for regulation initiation (Dixon et al., 2017; Kohn et al., 2014). Thus, it can be concluded that the regulation processes may not be adequately initiated in MDD (Gross, Uusberg, \& Uusberg, 2019). Notably, our execution seed did not show abnormal FC in MDD (Table 3). This model-based seed (angular gyrus, pre-SMA, and SMA) is supposed to be implicated in motor, somatosensory and language processes in order to generate a regulated emotional state (Kohn et al., 2014). Interestingly, the normal function of the execution seed amalgamates the sporadic evidences that MDD patients have enough executory capacity for re-imagination of scenes and congruent reinterpretation, however, they are not likely to make use of ER strategies spontaneously in everyday situations/non-instructed experiments (Ehring, Tuschen-Caffier, Schnülle, Fischer, \& Gross, 2010; Quigley \& Dobson, 2014). Nonetheless, if patients are exposed to well-justified instructions triggering the primary stages of regulation (i.e., evaluation and initiation), they will be subsequently able to implement the execution processes (Joormann \& Stanton, 2016; Liu \& Thompson, 2017). Generally, our findings are consistent with this well-established notion that various forms of psychopathologies (e.g., MDD) involve dysfunctionality in some, but not necessarily all of regulatory steps (Aldao, Nolen-Hoeksema, \& Schweizer, 2010; Gross et al., 2019; Khodadadifar et al., 2020).

Our second question was that how EP- and ER-related areas are interactively linked to regulatory behavior, and whether this interaction is disrupted in MDD. A previous model of healthy individuals indicated a normal balance between EP and ER processes. That is to say, higher amygdala reactivity prompts greater prefrontal activity, which in turn reflects greater regulatory behavior (Doré et al., 2017). Nonetheless, our bootstrapping analysis did not show any significant EP-ER findings in HC group (Table 4 and Figure 3). It seems that EPER homeostatic processes are mainly triggered in response to affective stimuli in healthy individuals. In our patient group, however, higher ALFF of right amygdala predicted lower ALFF of left DLPFC and weaker regulatory behavior in total. Although left DLPFC was not a "full" mediator (i.e., the indirect effect $\left(\beta\right.$ Amygdala $\rightarrow$ DLPFC ${ }^{*} \beta$ DLPFC $\rightarrow$ SEE) was non-significant), still it makes the total effect significant (Table 4 and Figure 3). That MDD patients, contrary to HC group, exhibited significant EP-ER findings in our task-free assessment was not quietly unexpected. Indeed, MDD individuals are usually encountered with endogenous ruminative thoughts which necessitates the continuous involvement of EP and ER processes, without exposure to exogenous affective stimuli (Davis, Foland-Ross, \& Gotlib, 2018; Disner et al., 2011). Nonetheless, the pattern of EP-ER interaction in MDD stands against the prototypic model of normal EP-ER (Doré et al., 2017). Reduced coupling of amygdala-prefrontal during reappraisal has been previously highlighted in MDD (Erk et al., 2010). Casual inferences from effective connectivity findings also indicated that amygdala hyperarousal is neither adequately transmitted to, nor sufficiently inhibited by cognitive control hubs (see (Stuhrmann, Suslow, \& Dannlowski, 2011) for attenuated bottom-up/top-down amygdala-prefrontal connections in MDD). In addition, behavioral evidences implied that higher values in stimulus-specific subjective arousal eventuates to inefficient and costly implementation of cognitive control strategies (Sheppes et al., 2014), specifically in people with greater depression scores (Deckert, Schmoeger, Auff, \& Willinger, 2019). Altogether, it seems that overburden of emotional reactivity in amygdala may inversely affect cognitive control processes in prefrontal cortices, which leads to diminished regulatory actions. Future task-based studies can test this hypothesis by directly manipulating amygdala arousal and tracking the elicited effects on mediated DLPFC recruitment and subsequent regulatory behavior in MDD.

Last but not least, we aimed to assess the association between depression severity and regional ALFF as well as whole-brain FC of EP- and ER-areas in MDD patients. We found that depression severity is not significantly correlated with the ALFF of EP- and ER-related seeds. Nonetheless, according to our FC analysis, the higher depression severity, the lower FC between the attention seed and right IPL. As previously mentioned, the parietal lobule is involved in attention switching (Beevers et al., 2010; Calder et al., 2007). The reduced connectivity of IPL is probably eventuated to attention biases which subsequently leads to negative affect (Disner et al., 2011; Disner, Shumake, \& Beevers, 2017). We also indicated that the higher depression severity, the lower FC between the initiation seed (DLPFC) and right VLPFC (Table 5 and Figure 4). The hypoconnectivity of frontoparietal regions is widely associated with dysfunctional cognitive control of emotions in MDD (Gudayol-Ferré, Peró-Cebollero, González-Garrido, \& Guàrdia-Olmos, 2015; Kaiser et al., 2015). It should be noted that several EP- and ER-related areas were regionally 
and/or connectively disturbed in our study, still not associated with depression severity. First, severity scales are checked by patients' declarations and clinicians' judgments, which are prone to various cognitive biases and thereby, partly confound the reliability/validity of the brain-behavior analyses. Second, the relationship of brain dysfunctionality with disorder severity may not be fairly detected by univariate analyses. That is to say, each disturbed neural structure may not be directly correlated with symptom severity, still modulates other circuitry(s) and indirectly affects depression severity.

The present study was not without limitations. First, we acknowledge that replicability at low sample sizes (i.e., 20 MDD and 32 healthy individuals) is relatively modest (Turner, Paul, Miller, \& Barbey, 2018). Second, the regulatory behavior was measured by SEE questionnaire in our study. Nonetheless, the generalizability of SEE findings to other established ER tasks and/or questionnaires (e.g., Emotion Regulation Questionnaire Gross \& John, 2003) should be further assessed. Third, although we included medicated patients for ecological validity, the resting-state networks are widely modulated by psychotropic medications (Tahmasian et al., 2015; Tahmasian et al., 2017; Wang et al., 2015) (see Greene, Black, \& Schlaggar, 2016 for pros/cons of recruiting a medicated sample). Fourth, there is heterogeneity in how people process and regulate complex emotions. Individual differences in various personality traits, psychodynamic characteristics of adult attachment and coping styles, and social-cognitive factors raise the possibility of person-centered neurobiological markers underlying EP and ER (John \& Gross, 2007; Scheffel et al., 2019). Thus, those individual differences should be considered in future studies to provide a more faithful representation of depression pathophysiology. Fifth, statistical mediation is not evidence for true EP-ER causality. Effective connectivity between amygdala and prefrontal cortex has been previously investigated in MDD (Stuhrmann et al., 2011), and needs to be further associated with regulatory behavior. Recent lesion- or TMSnetwork mapping (Padmanabhan et al., 2019; Siddiqi et al., 2020) may also help to reveal the interactions of EP- and ER-related areas with subsequent regulatory behavior. Finally, major depression is a disorder of heterogeneity (Buch \& Liston, 2020). Although low sample size did not allow us, but prospective studies can take relevant clinical factors (i.e., episode onset, number, duration, etc.) into consideration.

\section{5 | CONCLUSION}

Our study revealed the regional and/or connectivity alterations of EPand ER-related areas in MDD. According to the regional findings, an elevated emotion response (accentuated ALFF of right amygdala) and a diminished regulation initiation (attenuated ALFF of left DLPFC) was observed. According to the whole-brain FC findings, sensory and attention regions were connectively disturbed which probably suggest cognitive biases (enhanced FC between the visual/auditory and prefrontal areas as well as diminished FC between the attention and IPL areas). Furthermore, it might be assumed that regulation necessity is neither sufficiently detected (decreased FC between the VLPFC and IPS), nor adequately signaled for initiation (decreased FC between the
VLPFC and DLPFC). Our mediation analysis also indicated a contradictory EP-ER interaction in MDD; overburden of emotional reactivity in amygdala may inversely affect cognitive control processes in prefrontal cortices, which leads to diminished regulatory actions. Finally, depression severity was linked with FC of EP- (attention) and ERrelated (initiation) areas.

\section{ACKNOWLEDGMENTS}

This work was supported by German Research Foundation (SFB 779/A06 and DFG Wa2673/4-1 to MW), Centre for Behavioral and Brain Sciences Magdeburg (CBBS NNO5 to MW) and LeibnizGemeinschaft (Pakt für Forschung und Innovation to $\mathrm{MW}$ ). Abovementioned agencies had no further role in the study design, data collection, data analysis and interpretation, writing the results or in the decision to submit the paper for publication. We thank Renate BlobelLüer and Dr. Claus Tempelmann (Department of Neurology, OVGU) for MR data acquisition, Dr. J. Noack for data management and research assistants (M. Watermann, M. Nathan, K. Hahn, C. Foedisch) who helped with the data collection. Foremost, we appreciate our subjects for participating in this study.

\section{DATA AVAILABILITY STATEMENT}

The data that support the findings of this study are available from the corresponding author upon reasonable request.

\section{ORCID}

Amir Ebneabbasi (iD https://orcid.org/0000-0001-9348-5702

Anna Linda Leutritz (D) https://orcid.org/0000-0002-9650-8970

Mojtaba Zarei (D) https://orcid.org/0000-0002-1967-3139

Martin Walter (DD https://orcid.org/0000-0001-7857-4483

Masoud Tahmasian (D) https://orcid.org/0000-0003-3999-3807

\section{REFERENCES}

Aldao, A., Nolen-Hoeksema, S., \& Schweizer, S. (2010). Emotion-regulation strategies across psychopathology: A meta-analytic review. Clinical Psychology Review, 30(2), 217-237. https://doi.org/10.1016/j.cpr. 2009.11.004

Alkemade, A., Isaacs, B., Mulder, M., Groot, J., Berendonk, N., Lute, N., ... Forstmann, B. (2020). 3 versus 7 Tesla Magnetic Resonance Imaging for parcellations of subcortical brain structures.

Beck, A. T., \& Bredemeier, K. (2016). A unified model of depression. Clinical Psychological Science, 4(4), 596-619. https://doi.org/10.1177/ 2167702616628523

Beevers, C. G., Clasen, P., Stice, E., \& Schnyer, D. (2010). Depression symptoms and cognitive control of emotion cues: A functional magnetic resonance imaging study. Neuroscience, 167(1), 97-103. https://doi. org/10.1016/j.neuroscience.2010.01.047

Behr, M., \& Becker, M. (2012). Scales for experiencing emotions: awareness, appraisal and regulation of one's own emotions. Hellenic Journal of Psychology, 9, 278-303.

Behr, M., \& Becker, M. (2004). Skalen zum Erleben von Emotionen SEE [Scales for experiencing emotions], Hogrefe: Göttingen, Germany.

Beisteiner, R., Robinson, S., Wurnig, M., Hilbert, M., Merksa, K., Rath, J., ... Trattnig, S. (2011). Clinical fMRI: Evidence for a 7 T benefit over $3 \mathrm{~T}$. Neurolmage, 57(3), 1015-1021.

Bermpohl, F., Walter, M., Sajonz, B., Lücke, C., Hägele, C., Sterzer, P., ... Northoff, G. (2009). Attentional modulation of emotional stimulus 
processing in patients with major depression-Alterations in prefrontal cortical regions. Neuroscience Letters, 463(2), 108-113. https://doi. org/10.1016/j.neulet.2009.07.061

Brakowski, J., Spinelli, S., Dörig, N., Bosch, O. G., Manoliu, A., Holtforth, M. G., \& Seifritz, E. (2017). Resting state brain network function in major depression - Depression symptomatology, antidepressant treatment effects, future research. Journal of Psychiatric Research, 92, 147-159. https://doi.org/10.1016/j.jpsychires.2017.04.007

Buch, A. M., \& Liston, C. (2020). Dissecting diagnostic heterogeneity in depression by integrating neuroimaging and genetics. Neuropsychopharmacology, 46, 156-175. https://doi.org/10.1038/s41386-020-00789-3

Buhle, J. T., Silvers, J. A., Wager, T. D., Lopez, R., Onyemekwu, C., Kober, H., ... Ochsner, K. N. (2014). Cognitive reappraisal of emotion: A meta-analysis of human neuroimaging studies. Cerebral Cortex, 24 (11), 2981-2990.

Calder, A. J., Beaver, J. D., Winston, J. S., Dolan, R. J., Jenkins, R., Eger, E., \& Henson, R. N. (2007). Separate coding of different gaze directions in the superior temporal sulcus and inferior parietal lobule. Curr Biol, 17(1), 20-25. https://doi.org/10.1016/j.cub.2006.10.052

Cheng, C., Dong, D., Jiang, Y., Ming, Q., Zhong, X., Sun, X., ... Yao, S. (2019). State-related alterations of spontaneous neural activity in current and remitted depression revealed by resting-state fMRI. Frontiers in Psychology, 10(245). https://doi.org/10.3389/fpsyg.2019.00245

Davis, E. G., Foland-Ross, L. C., \& Gotlib, I. H. (2018). Neural correlates of top-down regulation and generation of negative affect in major depressive disorder. Psychiatry Research: Neuroimaging, 276, 1-8. https://doi.org/10.1016/j.pscychresns.2018.04.001

Deckert, M., Schmoeger, M., Auff, E., \& Willinger, U. (2019). Subjective emotional arousal: An explorative study on the role of gender, age, intensity, emotion regulation difficulties, depression and anxiety symptoms, and meta-emotion. Psychological Research., 84, 1857-1876. https://doi.org/10.1007/s00426-019-01197-z

Disner, S. G., Beevers, C. G., Haigh, E. A. P., \& Beck, A. T. (2011). Neural mechanisms of the cognitive model of depression. Nature Reviews Neuroscience, 12(8), 467-477. https://doi.org/10.1038/nrn3027

Disner, S. G., Shumake, J. D., \& Beevers, C. G. (2017). Self-referential schemas and attentional bias predict severity and naturalistic course of depression symptoms. Cognition and Emotion, 31(4), 632-644. https://doi.org/10.1080/02699931.2016.1146123

Dixon, M. L., Thiruchselvam, R., Todd, R., \& Christoff, K. (2017). Emotion and the prefrontal cortex: An integrative review. Psychological Bulletin, 143(10), 1033-1081. https://doi.org/10.1037/bul0000096

Donofry, S. D., Roecklein, K. A., Wildes, J. E., Miller, M. A., \& Erickson, K. I. (2016). Alterations in emotion generation and regulation neurocircuitry in depression and eating disorders: A comparative review of structural and functional neuroimaging studies. Neuroscience \& Biobehavioral Reviews, 68, 911-927. https://doi.org/10.1016/j.neubiorev. 2016.07.011

Doré, B. P., \& Ochsner, K. N. (2015). Emotion Regulation. In (pp. 53-58): Elsevier.

Doré, B. P., Weber, J., \& Ochsner, K. N. (2017). Neural predictors of decisions to cognitively control emotion. The Journal of Neuroscience, 37(10), 2580-2588. https://doi.org/10.1523/JNEUROSCI.2526-16.2016

Ehring, T., Tuschen-Caffier, B., Schnülle, J., Fischer, S., \& Gross, J. J. (2010). Emotion regulation and vulnerability to depression: Spontaneous versus instructed use of emotion suppression and reappraisal. Emotion, 10(4), 563-572. https://doi.org/10.1037/a0019010

Eickhoff, S. B., Stephan, K. E., Mohlberg, H., Grefkes, C., Fink, G. R., Amunts, K., \& Zilles, K. (2005). A new SPM toolbox for combining probabilistic cytoarchitectonic maps and functional imaging data. Neurolmage, 25(4), 1325-1335. https://doi.org/10.1016/j. neuroimage.2004.12.034

Erk, S., Mikschl, A., Stier, S., Ciaramidaro, A., Gapp, V., Weber, B., \& Walter, H. (2010). Acute and sustained effects of cognitive emotion regulation in major depression. J Neurosci, 30(47), 15726-15734. https://doi.org/10.1523/jneurosci.1856-10.2010

Etkin, A., Büchel, C., \& Gross, J. J. (2015). The neural bases of emotion regulation. Nature Reviews Neuroscience, 16(11), 693-700. https://doi. org/10.1038/nrn4044

Ferri, J., Eisendrath, S. J., Fryer, S. L., Gillung, E., Roach, B. J., \& Mathalon, D. H. (2017). Blunted amygdala activity is associated with depression severity in treatment-resistant depression. Cognitive, Affective, \& Behavioral Neuroscience, 17(6), 1221-1231. https://doi.org/10. 3758/s13415-017-0544-6

Friedrich, M.J. (2017). Depression is the leading cause of disability around the world. JAMA, 317(15), 1517.

Gray, J. P., Müller, V. I., Eickhoff, S. B., \& Fox, P. T. (2020). Multimodal abnormalities of brain structure and function in major depressive disorder: A meta-analysis of neuroimaging studies. Am J Psychiatry, 177 (5), 422-434. https://doi.org/10.1176/appi.ajp.2019.19050560

Greene, D. J., Black, K. J., \& Schlaggar, B. L. (2016). Considerations for MRI study design and implementation in pediatric and clinical populations. Dev Cogn Neurosci, 18, 101-112. https://doi.org/10.1016/j.dcn.2015. 12.005

Gross, J. J., \& John, O. P. (2003). Individual differences in two emotion regulation processes: Implications for affect, relationships, and well-being. J Pers Soc Psychol, 85(2), 348-362. https://doi.org/10.1037/00223514.85.2.348

Gross, J. J., Uusberg, H., \& Uusberg, A. (2019). Mental illness and wellbeing: An affect regulation perspective. World Psychiatry, 18(2), 130-139. https://doi.org/10.1002/wps.20618

Gudayol-Ferré, E., Peró-Cebollero, M., González-Garrido, A. A., \& GuàrdiaOlmos, J. (2015). Changes in brain connectivity related to the treatment of depression measured through fMRI: A systematic review. Frontiers in Human Neuroscience, 9. https://doi.org/10.3389/fnhum. 2015.00582

Hair, J. F., Ringle, C. M., \& Sarstedt, M. (2013). Partial least squares structural equation modeling: Rigorous applications, better results and higher acceptance. Long Range Planning, 46(1-2), 1-12. https://doi. org/10.1016/j.Irp.2013.01.001

Hair, J. F., Risher, J. J., Sarstedt, M., \& Ringle, C. M. (2019). When to use and how to report the results of PLS-SEM. European Business Review, 31(1), 2-24. https://doi.org/10.1108/EBR-11-2018-0203

Hamilton, J. P., Etkin, A., Furman, D. J., Lemus, M. G., Johnson, R. F., \& Gotlib, I. H. (2012). Functional neuroimaging of major depressive disorder: A meta-analysis and new integration of base line activation and neural response data. Am J Psychiatry, 169(7), 693-703. https://doi. org/10.1176/appi.ajp.2012.11071105

He, Z., Lu, F., Sheng, W., Han, S., Long, Z., Chen, Y., ... Chen, H. (2019). Functional dysconnectivity within the emotion-regulating system is associated with affective symptoms in major depressive disorder: A resting-state fMRI study. Australian \& New Zealand Journal of Psychiatry, 53(6), 528-539. https://doi.org/10.1177/0004867419832106

Heller, A. S., Johnstone, T., Peterson, M. J., Kolden, G. G., Kalin, N. H., \& Davidson, R. J. (2013). Increased prefrontal cortex activity during negative emotion regulation as a predictor of depression symptom severity trajectory over 6 months. JAMA Psychiatry, 70(11), 1181-1189. https://doi.org/10.1001/jamapsychiatry.2013.2430

Jaworska, N., Yang, X.-R., Knott, V., \& MacQueen, G. (2015). A review of $\mathrm{fMRI}$ studies during visual emotive processing in major depressive disorder. The World Journal of Biological Psychiatry, 16(7), 448-471. https://doi.org/10.3109/15622975.2014.885659

Jenkinson, M., Bannister, P., Brady, M., \& Smith, S. (2002). Improved optimization for the robust and accurate linear registration and motion correction of brain images. Neurolmage, 17(2), 825-841.

John, O. P., \& Gross, J. J. (2007). Individual differences in emotion regulation. In Handbook of emotion regulation (pp. 351-372). New York, NY: The Guilford Press. 
Joormann, J., \& Gotlib, I. H. (2010). Emotion regulation in depression: Relation to cognitive inhibition. Cognition \& Emotion, 24(2), 281-298. https://doi.org/10.1080/02699930903407948

Joormann, J., \& Stanton, C. H. (2016). Examining emotion regulation in depression: A review and future directions. Behaviour Research and Therapy, 86, 35-49. https://doi.org/10.1016/j.brat.2016.07.007

Kaiser, R. H., Andrews-Hanna, J. R., Wager, T. D., \& Pizzagalli, D. A. (2015). Large-scale network dysfunction in major depressive disorder. JAMA Psychiatry, 72(6), 603-603, 611. https://doi.org/10.1001/ jamapsychiatry.2015.0071

Kanske, P., Heissler, J., Schönfelder, S., \& Wessa, M. (2012). Neural correlates of emotion regulation deficits in remitted depression: The influence of regulation strategy, habitual regulation use, and emotional valence. Neurolmage, 61(3), 686-693. https://doi.org/10.1016/j. neuroimage.2012.03.089

Kelley, W. M., Wagner, D. D., \& Heatherton, T. F. (2015). In search of a human self-regulation system. Annu Rev Neurosci, 38, 389-411. https://doi.org/10.1146/annurev-neuro-071013-014243

Khodadadifar, T., Soltaninejad, Z., Ebneabbasi, A., Eickhoff, C., Sorg, C., Eimeren, T., ... Tahmasian, M. (2020). In search of convergent regional brain abnormality in cognitive emotion regulation: a transdiagnostic neuroimaging meta-analysis. https://doi.org/10.31234/osf.io/asrg6

Kohn, N., Eickhoff, S. B., Scheller, M., Laird, A. R., Fox, P. T., \& Habel, U. (2014). Neural network of cognitive emotion regulation - An ALE meta-analysis and MACM analysis. Neurolmage, 87, 345-355. https:// doi.org/10.1016/j.neuroimage.2013.11.001

LeMoult, J., \& Gotlib, I. H. (2018). Depression: A cognitive perspective. Clinical Psychology Review, 69, 51-66. https://doi.org/10.1016/j.cpr. 2018.06.008

LeWinn, K. Z., Strigo, I. A., Connolly, C. G., Ho, T. C., Tymofiyeva, O., Sacchet, M. D., ... Yang, T. T. (2018). An exploratory examination of reappraisal success in depressed adolescents: Preliminary evidence of functional differences in cognitive control brain regions. J Affect Disord, 240, 155-164. https://doi.org/10.1016/j.jad.2018.07.020

Li, B.-J., Friston, K., Mody, M., Wang, H.-N., Lu, H.-B., \& Hu, D.-W. (2018). A brain network model for depression: From symptom understanding to disease intervention. CNS Neuroscience \& Therapeutics, 24(11), 1004-1019. https://doi.org/10.1111/cns.12998

Li, W., Chen, Z., Wu, M., Zhu, H., Gu, L., Zhao, Y., ... Gong, Q. (2017). Characterization of brain blood flow and the amplitude of low-frequency fluctuations in major depressive disorder: A multimodal meta-analysis. J Affect Disord, 210, 303-311. https://doi.org/10.1016/j.jad.2016. 12.032

Lindquist, K. A., Wager, T. D., Kober, H., Bliss-Moreau, E., \& Barrett, L. F. (2012). The brain basis of emotion: A meta-analytic review. Behavioral and Brain Sciences, 35(3), 121-143. https://doi.org/10.1017/ S0140525X11000446

Liu, D. Y., \& Thompson, R. J. (2017). Selection and implementation of emotion regulation strategies in major depressive disorder: An integrative review. Clinical Psychology Review, 57, 183-194. https://doi.org/10. 1016/j.cpr.2017.07.004

Ma, X., Liu, J., Liu, T., Ma, L., Wang, W., Shi, S., ... Wang, M. (2019). Altered resting-state functional activity in medication-naive patients with firstepisode major depression disorder vs. healthy control: A quantitative meta-analysis. In Altered resting-state functional activity in medicationnaive patients with first-episode major depression disorder vs (p. 13(89)). Healthy Control: A Quantitative Meta-Analysis. Frontiers in Behavioral Neuroscience. https://doi.org/10.3389/fnbeh.2019.00089

Manoliu, A., Meng, C., Brandl, F., Doll, A., Tahmasian, M., Scherr, M., ... Sorg, C. (2014). Insular dysfunction within the salience network is associated with severity of symptoms and aberrant inter-network connectivity in major depressive disorder. Frontiers in Human Neuroscience, 7. https://doi.org/10.3389/fnhum.2013.00930

Martynova, E., West, S. G., \& Liu, Y. (2018). Review of principles and practice of structural equation modeling. Structural Equation Modeling: A
Multidisciplinary Journal, 25(2), 325-329. https://doi.org/10.1080/ 10705511.2017.1401932

Metzger, C. D., Eckert, U., Steiner, J., Sartorius, A., Buchmann, J. E., Stadler, J., ... Walter, M. (2010). High field FMRI reveals thalamocortical integration of segregated cognitive and emotional processing in mediodorsal and intralaminar thalamic nuclei. Frontiers in Neuroanatomy, 4, 138-138. https://doi.org/10.3389/fnana.2010.00138

Morawetz, C., Alexandrowicz, R. W., \& Heekeren, H. R. (2017). Successful emotion regulation is predicted by amygdala activity and aspects of personality: A latent variable approach. Emotion, 17(3), 421-441. https://doi.org/10.1037/emo0000215

Morawetz, C., Bode, S., Baudewig, J., \& Heekeren, H. R. (2017). Effective amygdala-prefrontal connectivity predicts individual differences in successful emotion regulation. Social Cognitive and Affective Neuroscience, 12(4), 569-585. https://doi.org/10.1093/scan/nsw169

Morawetz, C., Riedel, M., Salo, T., Berboth, S., Eickhoff, S., Laird, A., \& Kohn, N. (2020). Multiple large-scale neural networks underlying emotion regulation. Neuroscience \& Biobehavioral Reviews., 116, 382-395. https://doi.org/10.1016/j.neubiorev.2020.07.001

Morris, L. S., Kundu, P., Costi, S., Collins, A., Schneider, M., Verma, G., ... Murrough, J. W. (2019). Ultra-high field MRI reveals mood-related circuit disturbances in depression: A comparison between 3-tesla and 7-tesla. Translational Psychiatry, 9(1), 94-94. https://doi.org/10.1038/ s41398-019-0425-6

Mulders, P. C., van Eijndhoven, P. F., Schene, A. H., Beckmann, C. F., \& Tendolkar, I. (2015). Resting-state functional connectivity in major depressive disorder: A review. Neuroscience \& Biobehavioral Reviews, 56, 330-344. https://doi.org/10.1016/j.neubiorev.2015.07.014

Müller, V. I., Cieslik, E. C., Serbanescu, I., Laird, A. R., Fox, P. T., \& Eickhoff, S. B. (2017). Altered brain activity in unipolar depression revisited. JAMA Psychiatry, 74(1), 47-47, 55. https://doi.org/10.1001/ jamapsychiatry.2016.2783

Ochsner, K. N., Silvers, J. A., \& Buhle, J. T. (2012). Functional imaging studies of emotion regulation: A synthetic review and evolving model of the cognitive control of emotion. Annals of the New York Academy of Sciences, 1251(1), E1-E24. https://doi.org/10.1111/j.1749-6632. 2012.06751.x

Öner, S. (2018). Neural substrates of cognitive emotion regulation: A brief review. Psychiatry and Clinical Psychopharmacology, 28(1), 91-96. https://doi.org/10.1080/24750573.2017.1407563

Osada, T., Ohta, S., Ogawa, A., Tanaka, M., Suda, A., Kamagata, K., ... Konishi, S. (2019). An essential role of the intraparietal sulcus in response inhibition predicted by parcellation-based network. The Journal of Neuroscience: The Official Journal of the Society for Neuroscience, 39(13), 2509-2521. https://doi.org/10.1523/JNEUROSCI.2244-18. 2019

Padmanabhan, J. L., Cooke, D., Joutsa, J., Siddiqi, S. H., Ferguson, M., Darby, R. R., ... Fox, M. D. (2019). A human depression circuit derived from focal brain lesions. Biol Psychiatry, 86(10), 749-758. https://doi. org/10.1016/j.biopsych.2019.07.023

Palmer, S. M., Crewther, S. G., \& Carey, L. M. (2015). A meta-analysis of changes in brain activity in clinical depression. Frontiers in Human Neuroscience, 8. https://doi.org/10.3389/fnhum.2014.01045

Park, C., Rosenblat, J. D., Lee, Y., Pan, Z., Cao, B., lacobucci, M., \& McIntyre, R. S. (2019). The neural systems of emotion regulation and abnormalities in major depressive disorder. Behavioural Brain Research, 367, 181-188. https://doi.org/10.1016/j.bbr.2019.04.002

Picó-Pérez, M., Radua, J., Steward, T., Menchón, J. M., \& Soriano-Mas, C. (2017). Emotion regulation in mood and anxiety disorders: A metaanalysis of fMRI cognitive reappraisal studies. Progress in NeuroPsychopharmacology and Biological Psychiatry, 79, 96-104. https://doi. org/10.1016/j.pnpbp.2017.06.001

Quigley, L., \& Dobson, K. S. (2014). An examination of trait, spontaneous and instructed emotion regulation in dysphoria. Cognition and Emotion, 28(4), 622-635. https://doi.org/10.1080/02699931.2013.848786 
Riedel, M. C., Yanes, J. A., Ray, K. L., Eickhoff, S. B., Fox, P. T., Sutherland, M. T., \& Laird, A. R. (2018). Dissociable meta-analytic brain networks contribute to coordinated emotional processing. Human Brain Mapping, 39(6), 2514-2531. https://doi.org/10.1002/hbm. 24018

Rive, M. M., van Rooijen, G., Veltman, D. J., Phillips, M. L., Schene, A. H., \& Ruhé, H. G. (2013). Neural correlates of dysfunctional emotion regulation in major depressive disorder. A systematic review of neuroimaging studies. Neuroscience \& Biobehavioral Reviews, 37(10), 2529-2553. https://doi.org/10.1016/j.neubiorev.2013.07.018

Saberi, A., Mohammadi, E., Zarei, M., Eickhoff, S., \& Tahmasian, M. (2020). Structural and functional neuroimaging of late-life depression: $A$ coordinate- based meta-analysis. https://doi.org/10.31234/osf.io/y3n4a

Scheffel, C., Diers, K., Schönfeld, S., Brocke, B., Strobel, A., \& Dörfel, D. (2019). Cognitive emotion regulation and personality: An analysis of individual differences in the neural and behavioral correlates of successful reappraisal. Personality Neuroscience, 2, e11. https://doi.org/ 10.1017/pen.2019.11

Schilbach, L., Müller, V. I., Hoffstaedter, F., Clos, M., Goya-Maldonado, R., Gruber, O., \& Eickhoff, S. B. (2014). Meta-analytically informed network analysis of resting state FMRI reveals hyperconnectivity in an introspective socio-affective network in depression. PLOS One, 9(4), e94973-e94973. https://doi.org/10.1371/journal.pone.0094973

Schulze, L., Schulze, A., Renneberg, B., Schmahl, C., \& Niedtfeld, I. (2019). Neural correlates of affective disturbances: A comparative metaanalysis of negative affect processing in borderline personality disorder, major depressive disorder, and posttraumatic stress disorder. Biol Psychiatry Cogn Neurosci Neuroimaging, 4(3), 220-232. https://doi.org/ 10.1016/j.bpsc.2018.11.004

Shao, J., Meng, C., Tahmasian, M., Brandl, F., Yang, Q., Luo, G., ... Sorg, C. (2018). Common and distinct changes of default mode and salience network in schizophrenia and major depression. Brain Imaging and Behavior, 12(6), 1708-1719. https://doi.org/10.1007/s11682-0189838-8

Sheppes, G., Scheibe, S., Suri, G., Radu, P., Blechert, J., \& Gross, J. J. (2014). Emotion regulation choice: A conceptual framework and supporting evidence. Journal of Experimental Psychology: General, 143 (1), 163-181. https://doi.org/10.1037/a0030831

Siddiqi, S. H., Taylor, S. F., Cooke, D., Pascual-Leone, A., George, M. S., \& Fox, M. D. (2020). Distinct symptom-specific treatment targets for circuit-based Neuromodulation. Am J Psychiatry, 177(5), 435-446. https://doi.org/10.1176/appi.ajp.2019.19090915

Sladky, R., Baldinger, P., Kranz, G. S., Tröstl, J., Höflich, A., Lanzenberger, R., ... Windischberger, C. (2013). High-resolution functional MRI of the human amygdala at $7 \mathrm{~T}$. European Journal of Radiology, 82(5), 728-733. https://doi.org/10.1016/j.ejrad.2011.09.025

Song, Y., Shen, X., Mu, X., Mao, N., \& Wang, B. (2020). A study on BOLD fMRI of the brain basic activities of MDD and the first-degree relatives. International Journal of Psychiatry in Clinical Practice, 24, 1-9. https://doi.org/10.1080/13651501.2020.1744663

Song, Z., Zhang, M., \& Huang, P. (2016). Aberrant emotion networks in early major depressive disorder patients: An eigenvector centrality mapping study. Translational Psychiatry, 6(5), e819-e819. https://doi. org/10.1038/tp.2016.81

Stevens, J. S., \& Hamann, S. (2012). Sex differences in brain activation to emotional stimuli: A meta-analysis of neuroimaging studies. Neuropsychologia, 50(7), 1578-1593. https://doi.org/10.1016/j. neuropsychologia.2012.03.011

Streukens, S., \& Leroi-Werelds, S. (2016). Bootstrapping and PLS-SEM: A step-by-step guide to get more out of your bootstrap results. European Management Journal, 34(6), 618-632. https://doi.org/10.1016/j.emj. 2016.06.003

Stuhrmann, A., Suslow, T., \& Dannlowski, U. (2011). Facial emotion processing in major depression: A systematic review of neuroimaging findings. Biology of Mood \& Anxiety Disorders, 1(1), 10-10. https://doi. org/10.1186/2045-5380-1-10

Tahmasian, M., Bettray, L. M., van Eimeren, T., Drzezga, A., Timmermann, L., Eickhoff, C. R., ... Eggers, C. (2015). A systematic review on the applications of resting-state $\mathrm{fMRI}$ in Parkinson's disease: Does dopamine replacement therapy play a role? Cortex, 73, 80-105. https://doi.org/10.1016/j.cortex.2015.08.005

Tahmasian, M., Eickhoff, S. B., Giehl, K., Schwartz, F., Herz, D. M., Drzezga, A., ... Eickhoff, C. R. (2017). Resting-state functional reorganization in Parkinson's disease: An activation likelihood estimation meta-analysis. Cortex, 92, 119-138. https://doi.org/10.1016/j.cortex.2017.03.016

Tahmasian, M., Knight, D. C., Manoliu, A., Schwerthöffer, D., Scherr, M., Meng, C., ... Sorg, C. (2013). Aberrant intrinsic connectivity of hippocampus and amygdala overlap in the Fronto-insular and Dorsomedialprefrontal cortex in major depressive disorder. Frontiers in Human Neuroscience, 7. https://doi.org/10.3389/fnhum.2013.00639

Tarka, P. (2018). An overview of structural equation modeling: Its beginnings, historical development, usefulness and controversies in the social sciences. Quality \& Quantity, 52(1), 313-354. https://doi.org/ 10.1007/s11135-017-0469-8

Turner, B. O., Paul, E. J., Miller, M. B., \& Barbey, A. K. (2018). Small sample sizes reduce the replicability of task-based fMRI studies. Communications Biology, 1(1), 62-62. https://doi.org/10.1038/s42003-018-0073-z

van der Zwaag, W., Francis, S., Head, K., Peters, A., Gowland, P., Morris, P., \& Bowtell, R. (2009). fMRI at 1.5, 3 and 7 T: Characterising BOLD signal changes. Neurolmage, 47(4), 1425-1434.

Viviani, R. (2013). Emotion regulation, attention to emotion, and the ventral attentional network. Frontiers in Human Neuroscience, 7. https:// doi.org/10.3389/fnhum.2013.00746

Walter, M. (2017). Abstracts of the WASAD conference 2017, 14-16 September, Würzburg, Germany. Journal of Neural Transmission, 124 (10), 1277-1328. https://doi.org/10.1007/s00702-017-1777-9

Walter, M., Stadler, J., Tempelmann, C., Speck, O., \& Northoff, G. (2008). High resolution $\mathrm{fMRI}$ of subcortical regions during visual erotic stimulation at 7 T. Magma, 21(1-2), 103-111. https://doi.org/10.1007/ s10334-007-0103-1

Wang, L., Xia, M., Li, K., Zeng, Y., Su, Y., Dai, W., ... Si, T. (2015). The effects of antidepressant treatment on resting-state functional brain networks in patients with major depressive disorder. Hum Brain Mapp, 36(2), 768-778. https://doi.org/10.1002/hbm.22663

Wang, W., Zhao, Y., Hu, X., Huang, X., Kuang, W., Lui, S., ... Gong, Q. (2017). Conjoint and dissociated structural and functional abnormalities in first-episode drug-naive patients with major depressive disorder: A multimodal meta-analysis. Scientific Reports, 7(1), 10401-10401. https://doi.org/10.1038/s41598-017-08944-5

Wolfensberger, S. P., Veltman, D. J., Hoogendijk, W. J., Boomsma, D. I., \& de Geus, E. J. (2008). Amygdala responses to emotional faces in twins discordant or concordant for the risk for anxiety and depression. Neurolmage, 41(2), 544-552. https://doi.org/10.1016/j.neuroimage. 2008.01.053

Xia, M., Wang, J., \& He, Y. (2013). BrainNet viewer: A network visualization tool for human brain connectomics. PLOS One, 8(7), e68910. https://doi.org/10.1371/journal.pone.0068910

Xie, X., Mulej Bratec, S., Schmid, G., Meng, C., Doll, A., Wohlschläger, A., ... Sorg, C. (2016). How do you make me feel better? Social cognitive emotion regulation and the default mode network. Neurolmage, 134, 270-280. https://doi.org/10.1016/j.neuroimage.2016.04.015

Yan. (2010). DPARSF: A MATLAB toolbox for "pipeline" data analysis of resting-state fMRI. Frontiers in System Neuroscience. https://doi.org/ 10.3389/fnsys.2010.00013

Young, K. D., Siegle, G. J., Zotev, V., Phillips, R., Misaki, M., Yuan, H., ... Bodurka, J. (2017). Randomized clinical trial of real-time fMRI amygdala Neurofeedback for major depressive disorder: Effects on symptoms and autobiographical memory recall. The American Journal of 
Psychiatry, 174(8), 748-755. https://doi.org/10.1176/appi.ajp.2017. 16060637

Zanto, T. P., Rubens, M. T., Thangavel, A., \& Gazzaley, A. (2011). Causal role of the prefrontal cortex in top-down modulation of visual processing and working memory. Nature Neuroscience, 14(5), 656-661. https://doi.org/10.1038/nn.2773

Zhong, X., Pu, W., \& Yao, S. (2016). Functional alterations of fronto-limbic circuit and default mode network systems in first-episode, drug-naïve patients with major depressive disorder: A meta-analysis of restingstate fMRI data. J Affect Disord, 206, 280-286. https://doi.org/10. 1016/j.jad.2016.09.005

Zhou, M., Hu, X., Lu, L., Zhang, L., Chen, L., Gong, Q., \& Huang, X. (2017). Intrinsic cerebral activity at resting state in adults with major depressive disorder: A meta-analysis. Prog Neuropsychopharmacol Biol Psychiatry, 75, 157-164. https://doi.org/10.1016/j.pnpbp.2017.02.001

Zilverstand, A., Parvaz, M. A., \& Goldstein, R. Z. (2017). Neuroimaging cognitive reappraisal in clinical populations to define neural targets for enhancing emotion regulation. A systematic review. Neurolmage, 151, 105-116. https://doi.org/10.1016/j.neuroimage.2016.06.009
Zou, Q.-H., Zhu, C.-Z., Yang, Y., Zuo, X.-N., Long, X.-Y., Cao, Q.-J., ... Zang, Y.-F. (2008). An improved approach to detection of amplitude of low-frequency fluctuation (ALFF) for resting-state fMRI: Fractional ALFF. Journal of Neuroscience Methods, 172(1), 137-141. https://doi. org/10.1016/j.jneumeth.2008.04.012

\section{SUPPORTING INFORMATION}

Additional supporting information may be found online in the Supporting Information section at the end of this article.

How to cite this article: Ebneabbasi A, Mahdipour M, Nejati V, et al. Emotion processing and regulation in major depressive disorder: A 7T resting-state fMRI study. Hum Brain Mapp.

2021;42:797-810. https://doi.org/10.1002/hbm.25263 